that there is a considerable shortfall in specialist neurological services in the United Kingdom.'

The question arises as to whether or not the urgent/routine classification system is satisfactory. It is surprising that over $50 \%$ of new referrals were given a priority classification. This high figure may reflect the known long waiting time for "routine" patients, rather than a truly perceived seriousness of the medical condition. It is worth noting that some patients with serious disease were put on the non-urgent list, thus indicating that in some cases at least the initial priority category was inappropriate. More informative referral letters might assist consultants to classify patients appropriately.

In conclusion, this study highlights particularly: 1) the predominance of the diagnostic role of the neurology outpatient consultation; 2) the small proportion of patients referred with serious disease; 3 ) the unacceptably long waiting time, and 4) the inappropriate priority classification of some patients.

Mrs V A Wood gratefully acknowledges the help she received from Dr D T Wade, Consultant Neurologist, Rivermead Hospital, Oxford; Dr Pamela Enderby, District Speech Therapist, Frenchay Health Authority, and $\mathrm{Mr} \mathrm{H}$ Rothman, Reader in Management, Bristol Polytechnic, who advised and supervised her through her MPhil degree. Acknowledgement and thanks is also extended to Mrs Judith Weeks and Mrs Susan James, Higher Clerical Officers in the Department of Neurology, Frenchay Hospital, who kept a vigilant surveillance of medical case notes. CARD LANGTON HEWER MALCOLM J CAMPBELL Frenchay Hospital, Bristol BS16 1 LE JOHN RT COLLEY Department of Epidemiology and Public Health,
University of Bristol, Bristol, UK

Correspondence to: Mrs Wood.

We would be pleased to consider for publication short letters describing similar audit of outpatient practice in other countries.

1 Office of Health Economics. Compendium of health statistics 6th ed. 1987 London: OHE, 1987.

2 Perkin GD. Pattern of neurological outpatient practice: implications for undergraduate and postgraduate training. $J$ Roy Soc $\mathrm{Med}$ 1986;79:655-7.

3 Fraser RC, Patterson HR, Peacock E. Referrals to hospitals in an East Midlands Citymedical audit. 1974;24:304-19.

4 Stevens David L. Neurology in Gloucestershire: the clinical workload of an English neurologist. J Neurol Neurosurg Psychiatry 1989; 52:439-46.

5 Association of British Neurologists. A Report on Neurology Services in the United Kingdomnumber and distribution of consultants in adult neurology number and distribution of CT head scanners. Bristol: Frenchay Hospital, Department of Neurology, 1990.

\section{HTLV-1 infection: the clinical spectrum} widens

A neurological condition causing spastic paraparesis has long been recognised in the West Indies but it is only in recent years that the association between tropical spastic paraparesis (TSP) and human T-cell lymphotropic virus type 1 (HTLV-1) has been confirmed. ${ }^{1->}$ Serological tests for HTLV-1 can now support a diagnosis of TSP in patients with atypical clinical features.

Patient 1 was born in Jamaica and came to the United Kingdom at the age of 38 years. A the age of 61 years she presented with pain in her left shoulder, a three year history of difficulty raising her arms above her head, fatigue and inability to walk long distances.

On examination there was winging of both scapulae with weakness in the deltoids, triceps and biceps, without fasciculations. Distal upper limb musculature was normal. The biceps and supinator jerks were absent and the triceps jerks diminished. There was a mild spastic paraparesis with increased knee jerks, diminshed ankle jerks and extensor plantar responses. Sensory testing was normal. The creatine kinase was mildly elevated and muscle histology revealed neurogenic changes. Myelography and CSF examination were normal. There was a polyclonal increase in the serum immunoglobulins.

At first a diagnosis of motor neuron disease was considered but there was no change in her condition during the following four years and reinvestigation revealed serum antibodies against HTLV-1 in a titre of 1 in 6400 . In TSP, pain often accompanies or precedes weakness but is characteristically confined to the lower limbs and lumbar spine. This patient is also unusual in the severity of the muscle wasting which in TSP is seldom prominent and usually confined to the intrinsic hand muscles. ${ }^{4}$

Patient 2 was born in Jamaica and came to the United Kingdom aged 42 years. He was first seen aged 63 years following a single generalised convulsion; his right plantar response was extensor but there were no other neurological signs. CT brain scan and EEG were normal. Treponemal serology was positive (VDRL positive 1 in 4 ; TPHA positive; FTA IgG positive, IgM negative) without a history of previous venereal disease or yaws. Lumbar CSF was acellular with normal protein concentration and the tests for syphilis were all negative; Link's IgG index was 0.78 (upper limit of normal 0.58 ) suggesting intrathecal immunoglobulin synthesis. He was treated with a course of intramuscular procaine penicillin and regular oral phenytoin.

At the age of 70 years he was seen again for reassessment of his epilepsy. Only on direct questioning did he admit that his legs had become weak. He had difficulty rising from a low chair but otherwise his gait was normal There was a mild spastic paraparesis with brisk lower limb reflexes and the right plantar response was extensor as before. A CT brain scan was again normal. MRI scan showed several small punctate white matter lesions in both cerebral hemispheres but no abnormality of the spinal cord. Antibodies to HTLV-1 were detected in the serum in a titre of 1 in 8000 .

Patient 3 was born in British Guyana and came to the United Kingdom at the age of 34 years. At the age of 59 years she developed bilateral uveitis and was found to have positive treponemal serology (VDRL negative; TPHA positive; FTA IgG positive, IgM negative) without a past history of venereal infection or yaws. CSF contained 32 lymphocytes $/ \mathrm{mm}^{3}$ and the protein concentration was raised $(0.85 \mathrm{~g} / \mathrm{l})$; CSF tests for VDRL, TPHA and FTA were negative. Her vision responded to topical steroids and she took a one month course of oral doxycycline. Six months later she developed weakness and sensory loss in the legs which progressed over a year. At that time she had a spastic paraparesis with a sensory level at T10 and normal position sense. The upper limbs and cranial nerves were normal. Myelography was normal but was followed by urinary retention requiring catheterisation. The CSF on this occasion contained no cells but the protein concentration remained raised $(1.0 \mathrm{~g}$ 1). A diagnosis of neurosarcoidosis was considered but the patient showed no response to oral corticosteroid therapy; subsequent bronchoscopy, bronchial biopsy and Kveim test were found to be normal.

At follow up two years later her gait had deteriorated, she had developed mild bilateral nerve deafness and there was muscle wasting in both hands. Antibodies against HTLV-1 were detected in the serum in a titre of 1 in 64000 . The blood film was normal but there was a polyclonal increase in the serum immunoglobulins.

The initial detection of HTLV-1 antibodies was by gel particle agglutination assay and confirmed by more specific methods (ELISA, indirect immunoelectrophoresis, IgG antibody capture radio-immunoassay and Western blot techniques). ${ }^{5}$

These patients illustrate many of the recognised features of TSP but despite this, the illness in each of them had been tentatively attributed to another cause: motor neuron disease (patient 1), parasagittal tumour or neurosyphilis (patient 2), neurosarcoidosis or neurosyphilis (patient 3). The initial neurological presentations were pectoral pain and amyotrophy (patient 1), late-onset epilepsy (patient 2) and uveitis (patient 3) Tests for HTLV-1 antibodies clarified the diagnosis on these patients and should be performed in all West Indian patients with spastic paraparesis and with other unexplained neurological syndromes. If effective treatments for HTLV-1 infection become available, early diagnosis will be necessary to identify patients before severe, irreversible neurological damage has occurred. This will require greater awareness of the diverse ways in which TSP may present. The full spectrum of HTLV-1 infection remains to be defined.

$$
\begin{array}{r}
\text { RJ COLEMAN } \\
\text { M ZUCKERMAN } \\
\text { M SWASH } \\
\text { Departments of Neurology and Virology, } \\
\text { The Royal London Hospital, } \\
\text { London, UK }
\end{array}
$$

Correspondence to: Dr Coleman, Department of Neurology, Leeds General Infirmary, Great George Street, Leeds LS17 3EX, UK

1 Gessain A, Barin F, Vernant JC, et al. Antibodies to human $\mathrm{T}$ lymphotropic virus type 1 in patients with tropical spastic paraparesis. Lancet 1985;ii:407-10.

2 Newtom M, Cruickshank K, Miller D, et al. Antibodies to human $\mathrm{T}$ lymphotropic virus Antibodies to human T Tymph type 1 in to hesidents

3 Leading article. HTLV-1 comes of age. Lancet 1988;i:217-9.

4 Cruickshank JK, Rudge P, Dalgleish AG, et al Tropical spastic paraparesis and human $T$ cell lymphotropic virus type 1 in the United Kingdom. Brain 1989;112:1057-90.

5 White PMB. Comparison of assays for antibody to HTLV-1. J Clin Pathol 1988;41:700-2.

Temporal lobe phenomena during the aura phase of migraine attacks

I report a patient who often experienced temporal lobe phenomena:during the aura phase of his migraine attacks.

A 27 year old right handed computer 